\section{Reducing the Risk of Spinal Cord Infarction during Transforaminal Steroid Injections}

We read with great interest the recent report by Lyders and Morris ${ }^{1}$ of their case of spinal cord infarction following lumbar transforaminal epidural steroid injection. We would like to highlight the fact that not all corticosteroid preparations are associated with the same risk of embolization. ${ }^{2}$ There are 4 types of corticosteroid preparations commonly administered in clinical practice: methylprednisolone acetate (MPA), triamcinolone acetonide, betamethasone acetate, and dexamethasone sodium phosphate (DSP). The first 3 of these corticosteroid preparations are insoluble microcrystalline suspensions with varying potential to aggregate into larger particulates. Individual crystal sizes can range from 20 to $150 \mu \mathrm{m}$, which compares with an average red blood cell size of $7.5 \mu \mathrm{m}$. DSP, on the other hand, is completely soluble and clear of particulates at high-magnification microscopy.

A recently published in vivo animal study has compared the effects on the central nervous system (CNS) of the intra-arterial passage of insoluble MPA versus soluble DSP. ${ }^{3}$ This demonstrated that all animals that received MPA had serious neurologic sequelae and required ventilatory support. None of the animals that received an intra-arterial injection of soluble DSP had noticeable deficits.

On the basis of the current best evidence in the literature (case reports, animal experimentation, and in vitro microscopy), we suggest no longer performing transforaminal injections (cervical, tho- racic, or lumbar) with insoluble corticosteroid preparations. ${ }^{2} \mathrm{We}$ suggest using only DSP for these procedures. We believe this reduces, if not removes, the risk of CNS embolization during the procedure.

The only potential negative aspect of using DSP is the lack of data on the long-term efficacy of DSP compared with insoluble corticosteroids. A recent publication suggests there is no significant difference in the short term. ${ }^{4}$

\section{References}

1. Lyders EM, Morris PP. A case of spinal cord infarction following lumbar transforaminal epidural steroid injection: MR imaging and angiographic findings. AJNR Am J Neuroradiol 2009;30:1691-93

2. MacMahon PJ, Eustace SJ, Kavanagh EC. Injectable corticosteroid and loca anesthetic preparations: a review for radiologists. Radiology 2009;252:647-61

3. Okubadejo GO, Talcott MR, Schmidt RE, et al. Perils of intravascular methylprednisolone injection into the vertebral artery: an animal study. J Bone Joint Surg Am 2008;90:1932-38

4. Lee JW, Park KW, Chung SK, et al. Cervical transforaminal epidural steroid injection for the management of cervical radiculopathy: a comparative study of particulate versus non-particulate steroids. Skeletal Radiol 2009;38:1077-82

P.J. MacMahon

I. Crosbie

E.C. Kavanagh

Department of Radiology

Mater Misericordiae University Hospital

Dublin, Ireland 